\title{
A Supramolecular Synthon Containing Two Five-coordinate (Octaethylporphinato)Iron(III) Hemes
}

\author{
Jeffrey W. Haller ${ }^{1}$, Kenneth J. Haller $^{2}$, and Saifon A. Kohnhorst ${ }^{3}$ \\ ${ }^{1}$ Home School, P.O. Box 43, Chom Surang, Nakhon Ratchasima 30001 Thailand \\ ${ }^{2}$ School of Chemistry, Suranaree University of Technology, Nakhon Ratchasima 30000 Thailand, \\ ken.haller@gmail.com \\ ${ }^{3}$ Chemistry Program, Faculty of Science and Technology, Nakhon Ratchasima Rajabhat University, \\ Nakhon Ratchasima 30000 Thailand, saifon.k@nrru.ac.th
}

Analysis of structures and solid state resonance Raman spectra of a group of 5-coordinate high-spin iron(III) heme malaria pigment model systems led to the conclusion that supramolecular interactions play an integral role in the resonant Raman excitonic enhancement observed when applying near-infrared excitation wavelengths in $\beta$-hematin (malaria pigment $)^{[1]}$. A distinguishing feature of $\beta$-hematin which led to more supramolecular interactions compared to the other model systems was the $\mathrm{O}$-atoms in the propionic acid residues on $\beta$-hematin. A strategy to improve the OEP model systems was to use axial ligands containing $\mathrm{O}$-atoms, and indeed a better malaria pigment model complex, (picrato)(octaethylporphyrinato)Fe(III), has been prepared ${ }^{[2]}$. Two additional similar complexes have now been prepared: (2-hydroxy-3,5-dinitrobenzoato) ${ }^{[3]}$ and (4-methyl-2,6-dinitrophenolato) (octaethylporphinato)Fe(III).

In analyzing these structures we discovered a new highly concerted group of intermolecular $\mathrm{C}-\mathrm{H} \cdots \pi$ and $\mathrm{C}-\mathrm{H} \cdots \mathrm{O}$ interactions forming a supramolecular motif. There are six and eight $\mathrm{C}-\mathrm{H} \cdots \mathrm{O}$ intermolecular interactions in the picrato dimer and the $\mu_{2}$-dimer structures, respectively. In addition there are six intermolecular $\mathrm{C}-\mathrm{H} \cdots \pi$ interactions in each of the two dimer structures, 12 and 14 total concerted interactions, respectively. The third complex in this series, (4-methyl-2,6-dinitrophenolato)(OEP)Fe(III), has six intermolecular $\mathrm{C}-\mathrm{H} \cdots \pi$ interactions (the placement of the rings limits such $\mathrm{C}-\mathrm{H} \cdots \pi$ interactions to no more than eight possible). This dimer has a whopping 20 intermolecular $\mathrm{C}-\mathrm{H} \cdots \mathrm{O}$ interactions, making a total of 26 concerted interactions and firmly establishing this intriguing motif as another new supramolecular synthon. This synthon, together with the 3D packing/stacking dominated by porphyrin-porphyrin $\mathrm{C}-\mathrm{H}^{\cdots} \cdots \pi$ interactions supplemented by axial ligand-porphyrin hydrogen bonding interactions may help explain the similarity of the resonant Raman excitonic enhancement noted previously for $\beta$-hematin and the picrato model system.

\section{References:}

1. Puntharod; Webster; Asghari-Khiavi; Bambery; Safinejad; Rivadehi; Langford; Haller; Wood. J. Phys. Chem. B 2010 114(37), 12104-12115.

2. Puntharod; Haller; Robertson; Gwee; Izgorodina; Wood. J. Raman Spectrosc. 2017, 48(9), 1148-1157.

3. J. W. Haller; K. J. Haller; Kohnhorst. ACA Annual Meeting, 2018, Toronto, Canada. 